\title{
Acalculous biliary pain: Motility dysfunction and functional pain
}

\author{
Eldon A Shaffer MD FRCPC FACP FACG
}

M ost patients with gallstones (up to $80 \%$ ) experience a satisfactory outcome with relief of symptoms following surgery (1). Such a high response may in part be attributable to high patient expectations that their symptoms will worsen without surgery, their assumption being that surgery will provide a cure. Presumably this biliary-type pain originates either from obstruction of the gallbladder contracting against a fixed (eg, gallstone) or functional (eg, muscle spasm) obstruction at the cystic duct, or at the level of the sphincter of Oddi (SO), or from the inflammation (cholecystitis, cholangitis) that results. The basis of such pain is less clear if gallbladder smooth muscle contractility is defective, as occurs in cholesterol gallstone disease (2). Although biliary pain heralds cholelithiasis and cholecystitis, most (80\%) people harbouring gallstones never experience pain (3). Gallstones and abdominal pain are thus not necessarily synonymous. It is, therefore, not surprising that chronic abdominal pain persists in up to $50 \%$ following cholecystectomy (4). Many of these complaints are nonspecific, but $14 \%$ have true biliary pain attributable to a definable cause, eg, SO dysfunction (5). The figures for surgical failures might be higher with the advent of laparoscopic cholecystectomy, which has dramatically increased the rate of surgeries over the past decade. Predictors of this 'postcholecystectomy syndrome' include psychological vulnerability (6), chronic symptoms before cholecystectomy and pain six weeks after cholecystectomy.

The situation becomes even less clear when no structural abnormality is evident. Such 'functional' biliary type pain (7) (acalculous gallbladder disease) requires careful investigation to eliminate all structural abnormalities, particularly very small gallstones, as the basis for recurrent biliary-type pain. This includes repeating transabdominal ultrasound, which detects stones larger than 3 to $5 \mathrm{~mm}$ in diameter, performing an endoscopic ultrasound for tiny stones smaller than $3 \mathrm{~mm}$ in diameter and using accurate microscopy of gallbladder bile to detect microlithiasis (8). The accompanying article by Janowitz et al (pages 363-366) demonstrates that the lipid composition of human gallbladder bile remains stable even when frozen and stored. Although it is best to centrifuge bile immediately and use microscopy to detect cholesterol microcrystals and/or bilirubin granules, if a delay is unavoidable, bile can be frozen for later analysis.

The cholecystokinin (CCK)-provocation test can cause pain in some normal individuals, depending on the rate of CCK infusion. It does not, however, predict a symptomatic benefit from cholecystectomy and should be abandoned when evaluating acalculous biliary pain (9). More accurate is the quantitative measurement of gallbladder emptying under controlled conditions with a slow infusion of CCK CCK cholescintigraphy (7). In well defined patients with acalculous gallbladder disease and low ejection fractions on CCK ultrasonography, $59 \%$ to $75 \%$ continue to have symptoms (10,11). Conversely, some 90\% experience complete or substantial relief following cholecystectomy (11-13). Here, impaired gallbladder emptying appears to be a marker of acalculous biliary pain. The basis for such impaired gallbladder emptying is a defect in the contractile machinery (14).

Again, the dilemma is, what causes the pain? The biliary tract is a low-pressure conduit in which the gallbladder acts as a reservoir to decompress and regulate its pressure. Bile ducts lack a smooth muscle layer, leaving the $\mathrm{SO}$ a prime

Department of Medicine, University of Calgary, Calgary, Alberta

Professor and Head, Faculty of Medicine, University of Calgary, Regional Clinical Department Head, Department of Medicine, CRHA,

Foothills Hospital, Room C210, 1403-29 Street NW, Calgary, Alberta T2N 2T9. Telephone 403-670-1500, fax 403-670-1095,

e-mail eldon.shaffer@crha-health.ab.ca

Received for publication April 9, 2001. Accepted April 9, 2001 
suspect, especially when pain persists after cholecystectomy. The sphincter may be stenotic (from a fixed obstruction due to fibrosis and/or muscle hypertrophy) or exhibit dyskinesia (obstruction from muscular incoordination or hypertonicity). The diagnostic criteria outlined by the Rome II consensus conference include the gold standard test, SO manometry (7). This invasive procedure is best reserved for those with objective evidence of intermittent biliary obstruction. Patients suspected of having SO manometry should undergo a preliminary evaluation - a nuclear medicine scan that quantifies the transit time from the hepatic hilus to the duodenum (choledochoscintigraphy). Morphine provocation appears to increase its sensitivity (15). Those with SO stenosis have sufficient criteria for a fixed organic basis and benefit from going directly to sphincterotomy (7).

All functional biliary pain, however, might not relate to motility abnormalities of the gallbladder or the SO. Abnormal manometry of the sphincter may reflect a mere generalized motility disorder of the gut, perhaps involving the duodenum and jejunum (16). Conversely, visceral hypersensitivity, a potential basis for pain in functional gastrointestinal disorders, represents an abnormal sensitivity to a relatively innocuous stimulus. The basis for this could be modified receptor sensitivity at the level of the biliary tract (17) or adjacent viscus (duodenal hyperalgesia) (18), neuronal hyperexcitability in the dorsal horn of the spinal cord and/or altered central modulation of sensory inputs. Such biliary-type pain may even be part of the irritable bowel syndrome.

Thus, acalculous biliary pain means no obvious organic basis (structural or stone disease), but 'functional' is giving way to dysfunction, be it motor or sensory. Further, understanding the basis for the pain implies a potential for medical therapy, drugs acting specifically on the rich neural connections between the gallbladder, $\mathrm{SO}$ and the adjacent stomach and duodenum. Functional pain now has meaning.

\section{REFERENCES}

1. Black NA, Thompson E, Sanderson CF. Symptoms and health status before and six weeks after open cholecystectomy: a European cohort study. ECHSS Group. European Collaborative Health Services Study Group. Gut 1994;35:1301-5.

2. Xu QW, Shaffer EA: The potential site of impaired gallbladder contractility in an animal model of cholesterol gallstone disease. Gastroenterology 1996;110:251-7.

3. Gracie WA, Ransohoff DF. The natural history of silent gallstones. The innocent gallstones is not a myth. N Engl J Med 1982:307:798-800.

4. Ros E, Zambon D. Post-cholecystectomy symptoms. A prospective study of gall stones. Patients before and two years after surgery. Gut 1987;28:1500-4.

5. Bar-Meir S, Halpern Z, Bardan E, Gilat T. Frequency of papillary dysfunction among cholecystectomized patients. Hepatology 1984;4:328-330.

6. Jorgensen T. Abdominal symptoms and gallstone disease: an epidemiological investigation. Hepatology 1989;9:856-60.

7. Corazziari E, Shaffer EA, Hogan WJ, et al. Functional disorders of the biliary tract and pancreas. Gut 1999;45(Suppl II):II48-54.

8. Shaffer EA. Gallbladder sludge: what is its clinical significance? Curr Gastroenterol Rep 2001;3:166-73.

9. Smythe A, Majeed AW, Fitzhenry M. Johnson AG. A requiem for the cholecystokinin provocation test? Gut 1998;43:571-4.

10. Misra DC, Blossom GB, Fink-Bennett D, Glover JL. Results of surgical therapy for biliary dyskinesia. Arch Surg 1998;126:957-60.

11. Gonclaves RM, Harris JA, Rivera DE. Biliary dyskinesia: natural history and surgical results. Am Surg 1998;64:493-7.

12. Canfield AJ, Hetz SP, Schriver JP, et al. Biliary dyskinesia: a study of more than 2000 patients and review of literature. J Gastroenterol Surg 1998;2:443-8.

13. Yost F, Margethaler J, Presit M, et al. Cholecystectomy is an effective treatment for biliary dyskinesia. Am J Surg 1999;178:462-5.

14. Amaral J, Xiao Z-L, Chen Q, et al. Gallbladder muscle dysfunction in patients with chronic acalculous disease. Gastroenterology 2001;120:506-11.

15. Thomas PD, Turner JG, Dobbs BR, et al. Use of ${ }^{99 m} \mathrm{Tc}$-DISIDA biliary scanning with morphine provocation for the detection of elevated sphincter of Oddi basal pressure. Gut 2000;46:836-41.

16. Evans PR, Bak Y-T, Dowsett JF, Smith RC, Kellow JE. Small bowel dysmotility in patients with post-cholecystectomy sphincter of Oddi dysfunction. Dig Dis Sci 1997;42:1507-12.

17. Lasson A, Fork FT, Tragardh B, Zeferfeldt B. The postcholecystectomy syndrome: bile ducts are pain-trigger zone. Scand J Gastroenterol 1988;23:265-71.

18. Desautels SG, Slivka A, Hudson WR, et al. Postcholecystectomy pain syndrome: pathophysiology of abdominal pain in sphincter of Oddi type III. Gastroenterology 1999;116:900-5. 


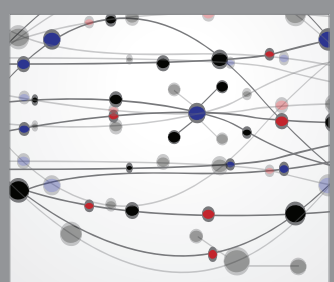

The Scientific World Journal
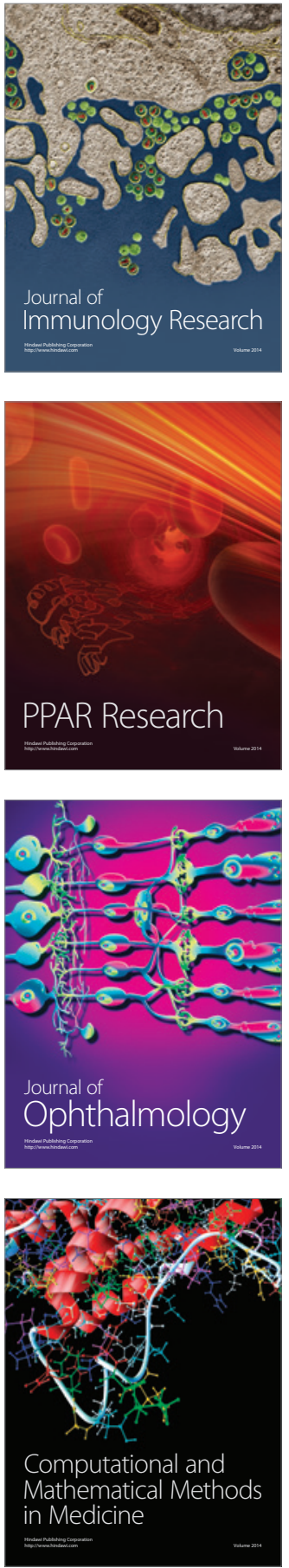

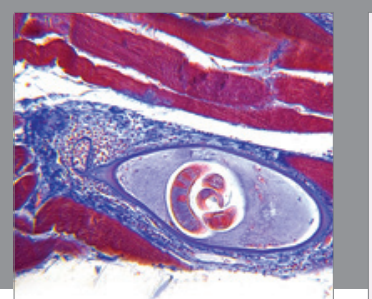

Gastroenterology Research and Practice

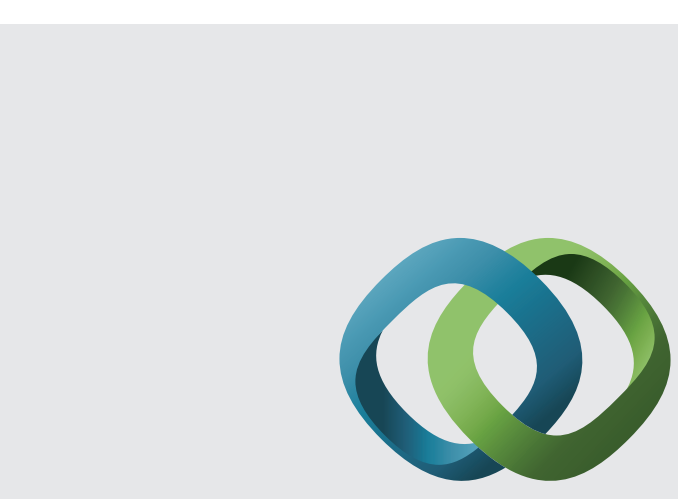

\section{Hindawi}

Submit your manuscripts at

http://www.hindawi.com
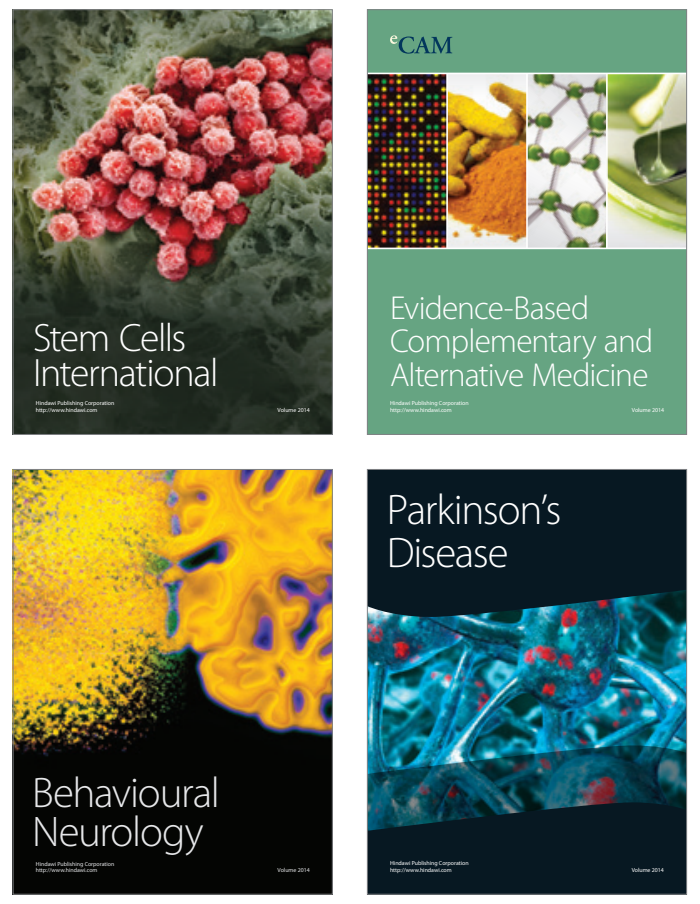
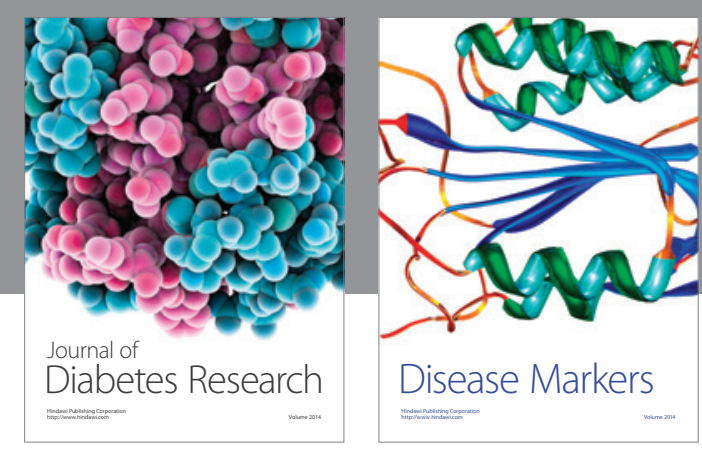

Disease Markers
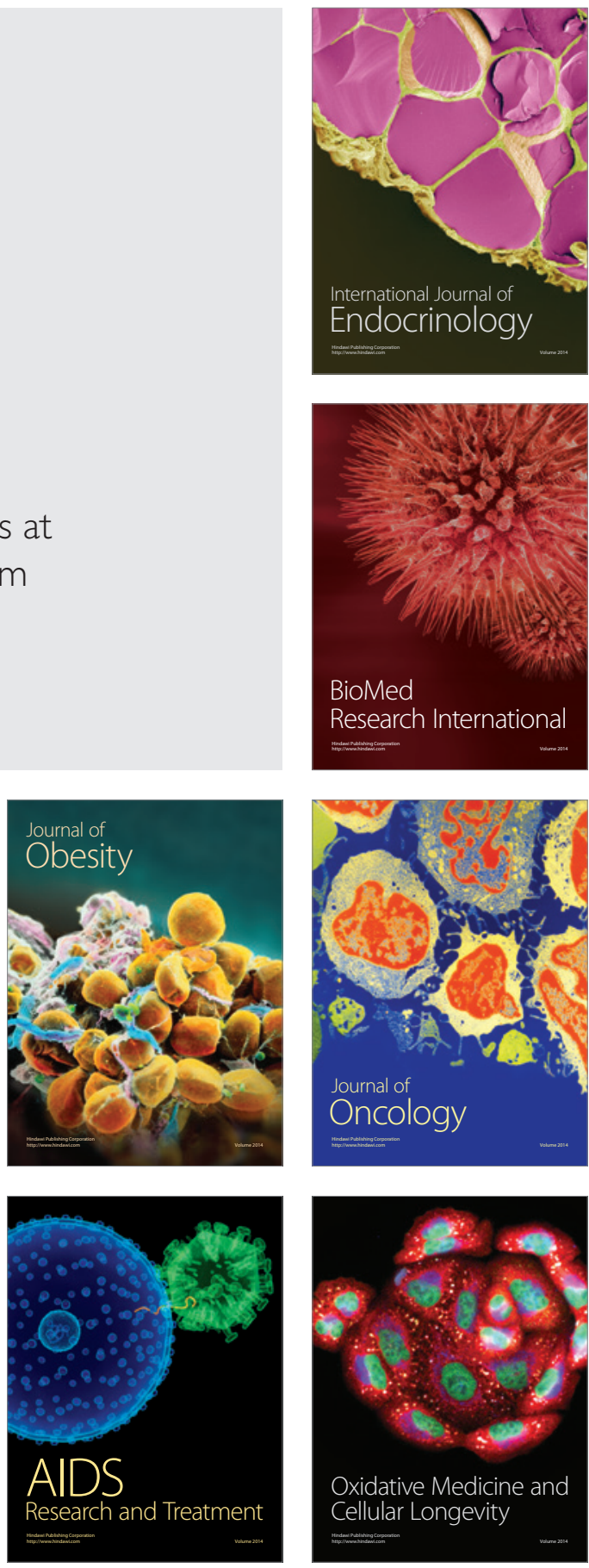